Article

\title{
Object-Based Flood Mapping and Affected Rice Field Estimation with Landsat 8 OLI and MODIS Data
}

\author{
Phuong D. Dao ${ }^{1,2}$ and Yuei-An Liou ${ }^{1,2, *}$
}

1 Center for Space and Remote Sensing Research, National Central University, Jhongli District, Taoyuan City 320, Taiwan; E-Mail: daoducphuong.tdb@gmail.com

2 Taiwan Group on Earth Observations, Zhubei City, Hsinchu County 30274, Taiwan

* Author to whom correspondence should be addressed; E-Mail: yueian@csrsr.ncu.edu.tw; Tel.: +886-3-422-7151 (ext. 57631); Fax: +886-3-425-4908.

Academic Editors: Clement Atzberger and Prasad Thenkabail

Received: 4 February 2015 / Accepted: 13 April 2015 / Published: 24 April 2015

\begin{abstract}
Cambodia is one of the most flood-prone countries in Southeast Asia. It is geographically situated in the downstream region of the Mekong River with a lowland floodplain in the middle, surrounded by plateaus and high mountains. It usually experiences devastating floods induced by an overwhelming concentration of rainfall water over the Tonle Sap Lake's and Mekong River's banks during monsoon seasons. Flood damage assessment in the rice ecosystem plays an important role in this region as local residents rely heavily on agricultural production. This study introduced an object-based approach to flood mapping and affected rice field estimation in central Cambodia. In this approach, image segmentation processing was conducted with optimal scale parameter estimation based on the variation of objects' local variances. The inundated area was identified by using Landsat 8 images with an overall accuracy of higher than 95\% compared to those derived from finer spatial resolution images. Moderate Resolution Imaging Spectroradiometer (MODIS) vegetation index products were utilized to identify the paddy rice field based on seasonal inter-variation between vegetation and water index during the transplanting stage. The rice classification result was well correlated with the statistical data at a commune level $\left(R^{2}=0.675\right)$. The flood mapping and affected rice estimation results are useful to provide local governments with valuable information for flooding mitigation and post-flooding compensation and restoration.
\end{abstract}


Keywords: object-based image analysis; segmentation; scale parameter estimation; flood mapping; paddy rice; Landsat; Moderate Resolution Imaging Spectroradiometer (MODIS); Cambodia

\section{Introduction}

The Mekong River is one of the 10 largest rivers in the world. It originates in the eastern watershed of the Tibetan Plateau and extends to the Mekong Delta. The river has formed a vast hydrological system with diverse ecosystems and multicultural communities along its basin. A rough number of 29.6 million people live within $15 \mathrm{~km}$ of its mainstream, including the majority of Cambodia's population, around 9.8 million people [1]. Under the effects of the tropical climate, there are many typhoons occurring in rainy seasons, resulting in a variety of long-lasting flood events along the Mekong river basin in history. The downside of flood disasters is that it resulted in serious negative effects on the psychology of local residents, food security, the environment, and the regional economy [2-8]. Flood events, on the contrary, play a vital role in agriculture by transporting and providing a huge amount of silt and fertilized sediment to feed the agricultural land in inundated areas [9-12]. The aquatic fauna is diversified and becomes a valuable source of protein for local people. According to the pros and cons of flooding, the goal and challenge of flood management and risk mitigation works are to reduce the negative impacts of flooding, but preserve its benefits. Cambodia is considered one of the most flood-vulnerable countries in Southeast Asia. The topography of the country is in the form of a cauldron-shape structure with a low floodplain along the Tonle Sap Lake and Mekong River in the middle, surrounded by plateaus and high mountains. Consequently, it often experiences extreme flash floods after heavy rainfall during monsoon seasons because rainwater normally concentrates in the vast middle lowland regions. Approximately $70 \%$ of its population resides in rural areas, along the main river system and lakes, and relies heavily on agricultural production. Accordingly, flood disasters can damage the livelihoods of the majority of Cambodians. The country witnessed a large-scale flood event during the rainy season in October 2013. A series of typhoons resulted in trans-boundary flash floods in the western regions along the Mekong River and Tonle Sap Lake. Many of the provinces affected during this disaster are the poorest regions of the country where poor farming communities, mainly relying on agricultural production, experienced the most severe consequences [13].

Paddy rice production has long been an important source of income in Cambodia, with a contribution of roughly $80 \%$ of Cambodia's Gross Domestic Product (GDP). Therefore, loss estimation in agriculture must be thoroughly investigated, especially from the flood impact on the paddy rice production in the area. Understanding the detailed impact information of rice fields helps the local authorities not only to implement rescue campaigns, but also to plan for the post-flood compensation and restoration program. In addition, rice monitoring and updates play an essential part in agricultural management and planning over flood-vulnerable regions after disasters. For example, a plan for a shift in the lowland paddy rice cropping calendar, or strategies on the improvement of flood resilience and irrigation system could be conducted based on the flood damage assessment results. 
Flooding can be identified using a variety of approaches such as statistics, ground-based gauging measurements, model prediction, remote sensing techniques, etc. Gauging station systems installed along rivers can provide water-level information for flood analysis. However, there exist difficulties in recording extreme flood events with high return period. Moreover, the density of those stations can be very sparse in developing countries, which limits their capability to assess the accurate significance and impact of flood events [6]. Statistical and model prediction approaches were applied to estimate or predict the potentially inundated area and impacts of future flood disasters [14-17]. These approaches are, unfortunately, not able to handle irregular changes induced by real objective causes. Therefore, the actual extent of flood disasters can be either under- or over-estimated. Remote sensing technology appears to be one of the most effective and fastest ways for observing and providing information on flood inundation extent and damage assessment over a wide area in a cost-effective manner, especially, radar remote sensing sensors, such as Synthetic Aperture Radar (SAR), which have the advantages of penetrating clouds and, to some extent, rainfall of microwave electromagnetic signals, and can capture and provide users with clear views of the inundation extent $[4,18,19]$. However, the number of radar remote sensing satellites is limited, and their images are commonly expensive and unavailable for public use. Hence, optical remote sensing imagery still has its role in flooding mapping as it has high temporal resolution and rich spectral information. Thus, previously inundated regions can be identified several days after the evacuation of flood water based on the changes in spectral properties between pre- and post-flood images [12]. Landsat and MODIS satellite data, provided free of charge by NASA, are great candidates for flood mapping and damage assessment for large-scale flood disasters.

Traditional pixel-based image analysis algorithms for flood mapping and land use classification suffer from low accuracy, sub-pixel problems, and the speckle noise effect in the resulting images [2022]. On the other hand, the object-based image analysis (OBIA) approach has been thoroughly developed in the last two decades to overcome the limitations and disadvantages of the traditional pixel-based approaches by generating and analyzing meaningful image objects instead of individual pixels and reducing the speckle noise effect. The OBIA approach is conducted through a two-step process: (1) image segmentation by aggregating a number of individual pixels or image sub-objects to form larger objects (primitive objects) based on the homogeneity, intensity, and texture of each investigated image; and (2) image classification and feature extraction. The result of the OBIA approach was successfully proved to be more accurate than that of the pixel-based approaches for land cover classification in recent studies, such as discrimination of different species of mangroves with Worldview-2 imagery [23], flood area delineation in the trans-boundary areas using the ENVISAT/ASAR and Landsat TM data [4], and crop mapping using the multi-temporal Landsat imagery [22]. Other applications of the object-based method for flood water and wetland mapping were introduced in [24-26]. The object-based approach is normally used for the high spatial resolution images with a pixel size smaller than those of the objects of interest [27,28]. The application of this method for the coarse resolution imagery is less common as the pixel size is larger than the object, and the image can be under-segmented. However, the image segmentation can be employed at different resolutions to create homogeneous regions based on spatial and spectral information for identifying various objects at different scales and sizes. Many studies have been conducted [28-32] using the OBIA approach for the MODIS data, and acquired great results in the large-scale land cover mapping of biomass, forest cover, rice crop, snow, and so on. 
The aim of this study was to introduce a thorough procedure to map the inundation extent and estimate the affected paddy rice field area after the Cambodian flood of October 2013 using 16-day Landsat 8 OLI Level 1 standard and 8-day MODIS vegetation index products. The OBIA approach was applied for the image classification with a new improved estimation algorithm with optimal scale parameter in the segmentation process to obtain more accurate results in the flood damage assessment. The detailed estimate of the affected paddy rice areas provides essential information for post-flood compensation and future rice crop restoration in the damaged regions.

\section{Study Area and Data}

\subsection{Study Area}

Cambodia borders Thailand to the northwest, Laos to the northeast, Vietnam to the east, and the Gulf of Thailand to the southwest. Due to the availability of satellite data during the flood event, this study emphasized on the central region (Figure 1) of the country, which is located between $10^{\circ} 30^{\prime} \mathrm{N}$ and $13^{\circ} 45^{\prime} \mathrm{N}$ in latitude, and $103^{\circ} 25^{\prime} \mathrm{E}$ and $106^{\circ} 15^{\prime} \mathrm{E}$ in longitude. The majority of the land area is an elevation below $40 \mathrm{~m}$, at which it is vulnerable to flooding. During the monsoon season, from August to November, the mean precipitation is about $1750 \mathrm{~mm}$ per year and the mean temperature is roughly $32{ }^{\circ} \mathrm{C}$. The region experienced a devastating flood event overwhelming a vast area of land along both sides of the Mekong River and Tonle Sap Lake in October 2013. According to the statistics obtained from the National Committee for Disaster Management [13], 377,354 households were affected, 1.8 million people were evacuated from danger, and 168 people died during the event. Farmers facing high levels of crop damage in one of Cambodia's main rice-producing regions suffered from sizeable adverse effects on their livelihoods, particularly for those districts that have experienced consecutive years of crop damage.

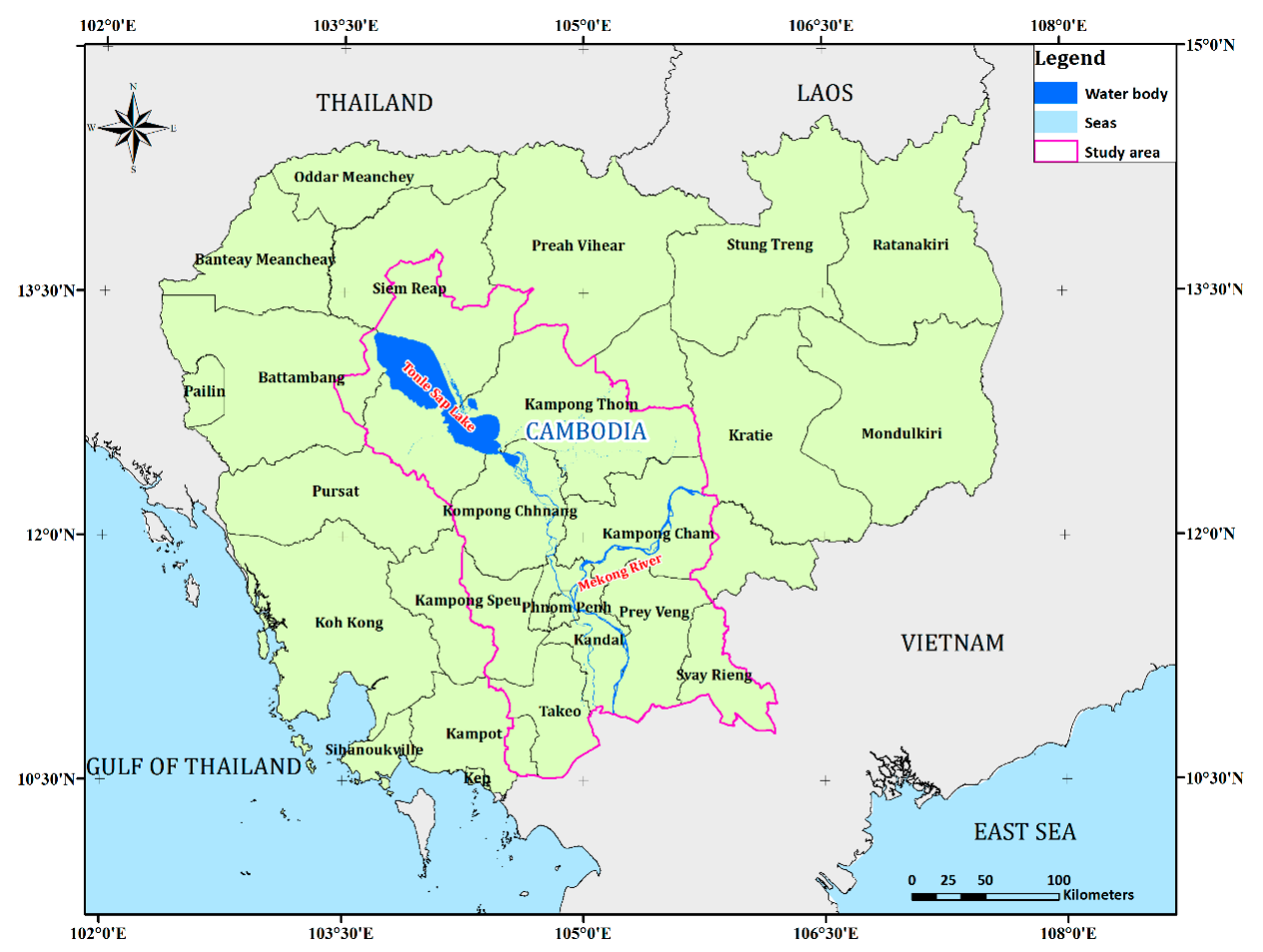

Figure 1. The 2013 flood location map in the central region of Cambodia. 
According to [33-35], there are two main crop seasons in Cambodia: wet season rice (from May to November), mainly cultivated in the low floodplain regions, occupying roughly $85.5 \%$ of the total rice area; and dry season rice (from the beginning of November to April of the next year), covering about $14.5 \%$ of the total rice area. Accordingly, the flood of October 2013 only caused damage to the wet season paddy rice in the lowland regions.

\subsection{Data}

\subsubsection{Landsat 8 OLI Imagery}

The flood-inundated areas were identified using Landsat 8 OLI images captured before and after the flood event. All images were orthorectified and georeferenced to the UTM projection, zone 48, and converted to digital numbers (DNs) to provide the users with Landsat standard Level 1 products [36]. The product consists of eight multispectral bands with a spatial resolution of 30 meters, one panchromatic band with a resolution of 15 meters, and two thermal bands collected at 100 meters, but resampled to 30 meters to match the OLI multispectral bands. All raw images with DN values were atmospherically corrected to obtain the surface reflectance images [36,37]. For the atmospheric correction, the images were first calibrated to at-sensor radiance images, and then corrected to surface reflectance images using the Fast Line-of-sight Atmospheric Analysis of Hypercubes (FLAASH) tool based on the MODTRAN radiative transfer model in ENVI software [38]. Four multispectral bands were selected for this flood mapping study: Green (530-590 nm), Red (640-670 nm), Near Infrared (850-880 nm), and Shortwave Near Infrared (SWIR1) (1570-1650 nm). The Landsat data information is given in Table 1.

Table 1. The Landsat 8 OLI images used in this study.

\begin{tabular}{ccccc}
\hline No. & Pre-Flood Image & Acquisition Date & Post-Flood Image & Acquisition Date \\
\hline 1 & LC81260512013137LGN01 & 17 May 2013 & LC81260512013297LGN00 & 24 October 2013 \\
2 & LC81260522013137LGN01 & 17 May 2013 & LC81260522013297LGN00 & 24 October 2013 \\
3 & LC81260532013137LGN01 & 17 May 2013 & LC81260532013297LGN00 & 24 October 2013 \\
4 & LC81250522013146LGN00 & 26 May 2013 & LC81270512013304LGN00 & 31 October 2013 \\
5 & LC81270512013160LGN00 & 9 June 2013 & LC81250522013306LGN00 & 2 November 2013 \\
6 & LC81270512013176LGN00 & 25 June 2013 & LC81250532013306LGN00 & 2 November 2013 \\
7 & LC81250522013178LGN01 & 27 June 2013 & -- & -- \\
\hline
\end{tabular}

Some regions were covered by sparse and speckle clouds in both pre- and post-flood images, which can lead to underestimation of the flood inundation area. However, the cloud contamination level only varied between about $1 \%$ and $3 \%$ over the inundation regions, according to the information presented in the quality assurance (QA) band, and will be masked out in the classification step.

\subsubsection{MODIS Vegetation Index Product}

For the classification of the paddy rice field, we used Terra (MOD13Q1) and Aqua (MYD13Q1) MODIS vegetation index (VI) products. The VI products are provided every 16 days at a spatial resolution of 250 meters as gridded level-3 products in the Sinusoidal projection. Both 16-day 
MOD13Q1 and MYD13Q1 products were produced from the daily surface reflectance products. The Terra 16-day period starts from day 001, while the Aqua 16-day period starts from day 009 [39]. Hence, by combining the two data, we get eight-day vegetation index products, which provide the users with finer temporal resolution for monitoring the phenological and seasonal changes of the paddy rice. The VI products consist of Normalized Difference Vegetation Index (NDVI), Enhanced Vegetation Index (EVI), and four spectral bands: Blue (459-479 nm), Red (620-670 nm), Near Infrared (841-876 nm), and Shortwave Near Infrared (SWIR-2) (2105-2155 nm). Land Surface Water Index can be calculated from bands NIR and SWIR-2 $\left(\right.$ LSWI $\left._{2130}=(\mathrm{NIR}-\mathrm{SWIR}-2) /(\mathrm{NIR}+\mathrm{SWIR}-2)\right)$. Bands Blue and Shortwave Near Infrared (SWIR-2), with an original resolution of 500 meters, were resampled to a resolution of 250 meters, the same resolution as the Red and NIR bands. The data were transformed to the UTM projection, zone 48, the same as that of Landsat images.

\subsubsection{Ancillary Data}

In addition to the satellite data mentioned above, the 30-m ASTER global digital elevation model version 2 (GDEM2) was additionally used to mask out the non-rice and non-water areas in the image classification process. The GDEM2 was significantly enhanced over the GDEM1 by adding 260,000 additional stereo-pairs, which were able to improve the coverage and reduce the occurrence of artifacts. The model was upgraded to improve the vertical and horizontal accuracy, and give superior water body coverage and detection. For paddy rice detection, the GDEM2 was resampled to a spatial resolution of $250 \mathrm{~m}$, the same resolution as that of the MODIS VI products. The slope images were produced from the GDEM2, and were used, in combination with the elevation images, to generate masks for flood mapping and paddy rice detection.

For flood mapping validation, reference flood maps were employed to validate the accuracy of the flood map derived from this study. Due to a lack of ground-based measurements, we alternatively used the inundation maps derived from the high spatial resolution satellite imagery for the validation process. The first validation data came from the flood extraction results of the Pleiades satellite pan-sharpened image collected on October 22 with a spatial resolution of 0.5 meters. The second one was from the flood classification results of the Disaster Monitoring Constellation (DMC) satellite data captured on October 24 at 22-m spatial resolution. These data were produced by the United Nations Institute for Training and Research/Operational Satellite Applications Program (UNITAR/UNOSAT), provided to users through the website of the International Charter for Space and Major Disasters in shapefile format and UTM projection. For the derivation of these data, the satellite images were slightly downgraded in the areas directly proximate to the Armistice Demarcation Line to minimize the effects on the later image analysis. These images were preprocessed and georeferenced to the UTM coordinate system. The images were then classified to extract land cover information as well as flood inundation regions. The flood map derived from the DMC and Pleiades data were validated by visual inspection and compared with the manually digitized flood maps. The high-resolution Google Earth images were also used to better visualize the ground conditions and compensate for the intermittent haze, cloud cover, and other disturbances.

For paddy rice detection, a statistical rice area and ratio map at commune level (Table 2), upgraded in 2013, was introduced for the accuracy assessment of the MODIS-derived rice map. The data was 
downloaded from the open data website of Open Development Cambodia, which provides public users with up-to-date and accurate information about Cambodia and its economic and social development. For validation of the estimated affected rice field, the number of affected rice areas derived from the approach was compared with the statistical data provided by the Cambodian government report [13]. The rice cropping calendar was introduced to assist the separation of the rice growth phenology for the paddy rice field classification, as well as to specify which rice season was impacted by the flood event.

Table 2. Commune-level paddy rice statistical data updated in 2013.

\begin{tabular}{ccccc}
\hline No. & Province & Commune & Ratio & Rice Area (ha) \\
\hline 1 & Prey Veng & Preaek Changkran & 30.90 & 238.65 \\
2 & Prey Veng & Pnov Ti Muoy & 55.48 & 1973.55 \\
3 & Prey Veng & Rumlech & 89.46 & 2772.24 \\
4 & Prey Veng & Lve & 49.89 & 866.41 \\
5 & Prey Veng & Chrey Khmum & 95.61 & 3569.07 \\
\hline 117 & Svay Rieng & Doung & 57.82 & 3200.66 \\
118 & Svay Rieng & Trapeang Sdau & 76.27 & 4275.11 \\
119 & Svay Rieng & Angk Prasrae & 84.03 & 2538.65 \\
120 & Svay Rieng & Chantrei & 75.17 & 2090.40 \\
\hline 196 & Svay Rieng & Thmei & 87.83 & 3502.71 \\
\hline
\end{tabular}

The dry season rice, transplanted from November to April, was not impacted by the flood that occurred in October 2013. Therefore, it was not included in the flood damage assessment. As a consequence, we omitted the communes, which include the amount of dry season rice area before conducting the validation process.

\section{Methodology}

Overall design of the study consists of four main parts: (1) flood mapping using Landsat 8 OLI imagery; (2) paddy rice crop monitoring and detection with MODIS vegetation index data; (3) flood affected rice field estimation; and (4) validation. The flow chart of the study is illustrated in Figure 2.

\subsection{Image Segmentation}

The main purpose of the image segmentation is to merge the single image pixels or sub-objects to form a larger image object based on criteria over the spectral and spatial properties [40-43]. The multiresolution segmentation algorithm used in the eCognition software is an iterative process of local optimization based on the average homogeneity of the created objects. The measure of the homogeneity includes the spectral and spatial components. The spectral homogeneity is defined as the average values of the generated objects. Meanwhile, the spatial homogeneity is formed by the two shape features: smoothness (the ratio between the perimeter of the object and the perimeter of the minimum boundary rectangle) and compactness (the ratio between the perimeter of the segment and the square root of its area) [41]. Thus, the segments, in comparison with single pixels, have richer spectral information, such as object's mean values per band, median values, minimum and maximum values, mean ratios, variance, and so on. However, the merging process can lead to over- or 
under-segmentation. The over-segmentation can be further solved in the classification phase, while the under-segmentation phenomenon undoubtedly leads to distortion of the later feature extraction and classification process [44]. Hence, the optimal scale parameter must be taken into consideration to obtain the best segmentation result.

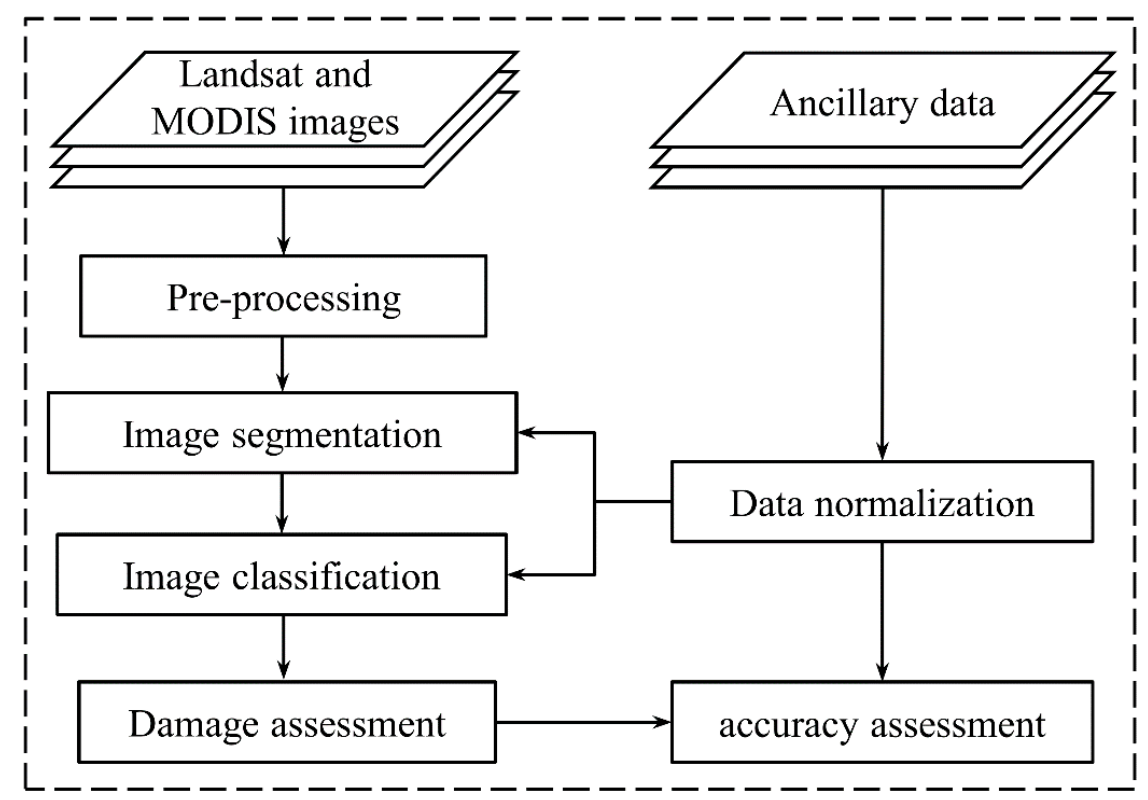

Figure 2. Overall design flow chart of the study.

In this study, local variance (LV), measured as the mean value of the standard deviation of the image objects, was used as the basis of estimating the optimal scale parameter [44-46]. The local variance of an object was computed from all pixels contained within that object. The images were repeatedly segmented at different scale factors using the bottom-up multiresolution segmentation approach. The local variance and its rate of change (ROC) of an entire image were then computed by using the mean standard deviation of all objects in the segmented image. With the bottom-up segmentation approach, the local variances of the image objects gradually rise over the increase of the scale parameters because of changes in the level of objects' homogeneity. Simultaneously, the size of a segment grows and its local variance increases continuously until it reaches the level where the segment fits its object in the real world [45]. Theoretically, when the boundary of the segment exceeds the meaningful object, the level of object homogeneity decreases. Consequently, the local variance increases sharply. Thus, the rate of change of local variance is a good indicator for the estimation of the optimal scale parameter for the image segmentation. The ROC was computed as given in the following equation:

$$
R O C=\left(\frac{L V_{n}-L V_{n-1}}{L V_{n-1}}\right) \times 100,
$$

where $L V_{\mathrm{n}}$ is the local variance of level $\mathrm{n}$ and $L V_{\mathrm{n}-1}$ is the local variance of level $n-1$. A graph of local variance of the segmented image was constructed to investigate its variation over the change of the scale factors. The distinguished scale parameters are supposed to be at the peak points in the line graph of the local variance or the rate of change where the local variance varies abruptly. The optimal scale parameter is at the finest level. In practice, the local variance, occasionally, changes smoothly over the 
alteration of the scale parameter, while the ROC graph is more distinguished and it is easier to find the optimal scale parameter based on this indicator.

In this research, we segmented the images at 50 scale parameters from 1 to 50 using the bottom-up hierarchical multiresolution segmentation approach with shape $=0.1$ and compactness $=0.5$ for constructing the $L V$ graphs. The graphs of local variance and rate of change for the Landsat 8 and MODIS images are shown in Figure $3 a$ and b, respectively. As seen from the ROC graphs, the optimal scale parameter for segmenting the Landsat mosaicked images is 23 at the first peak point, where the local variance changes abruptly. Similarly, the scale parameter of 11 is identified as optimal for the segmentation of the MODIS images as it exposes the same phenomenon.
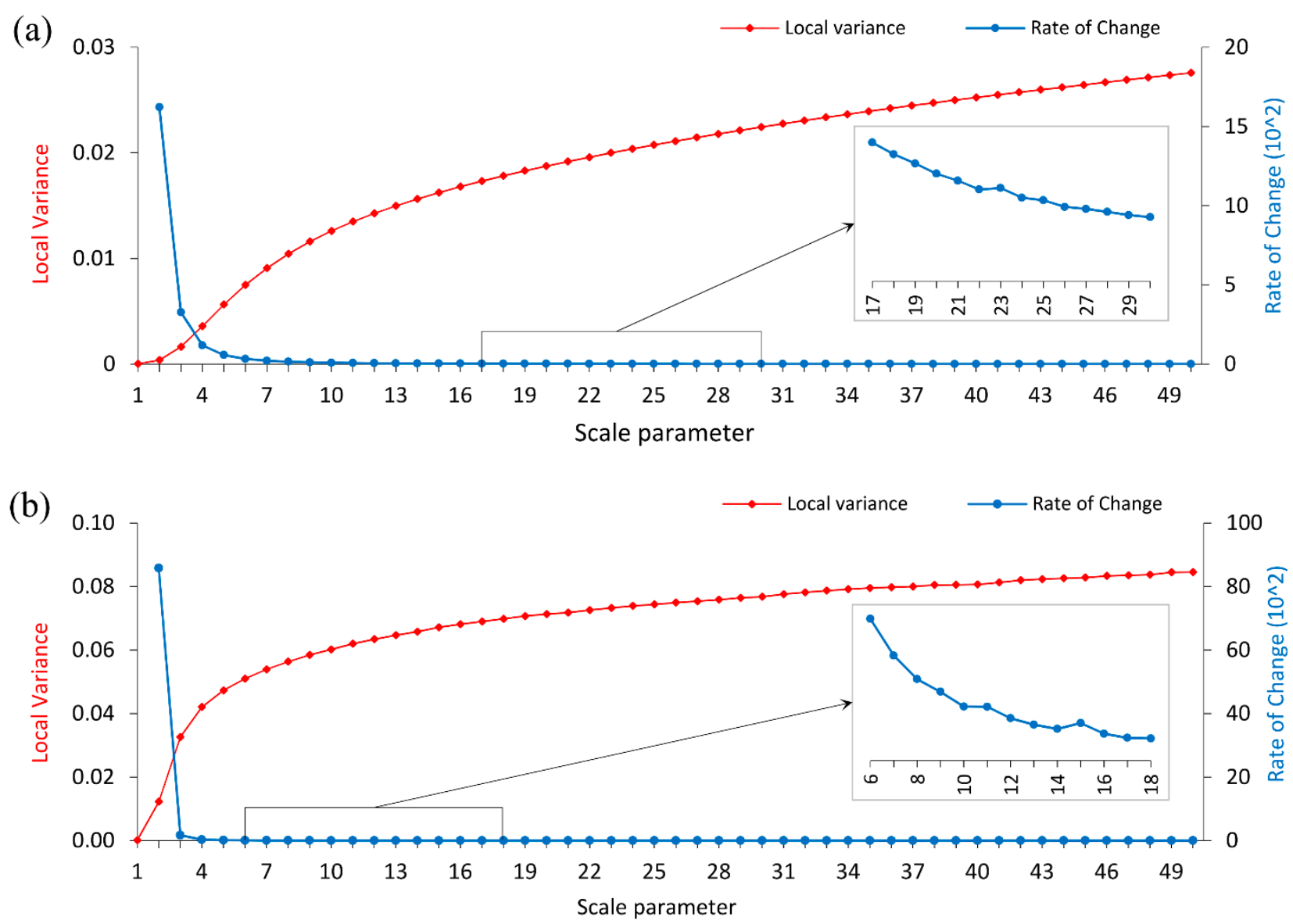

Figure 3. Graphs of local variance and its rate of change: (a) for segmenting Landsat 8 images; and (b) for segmenting MODIS time series (shape: 0.1 and compactness: 0.5).

Unmistakably, the spatial resolution of the MODIS images is relatively coarser than that of Landsat images. Therefore, the homogeneity criteria were reached faster in the iterative segmentation process. Consequently, the optimal scale parameter of the MODIS time series was smaller than that of the Landsat images. After the segmentation step, all the segmented images were used as inputs of the later classification process for further extraction of the flood inundation and detection of the paddy rice field. 


\subsection{Image Classification}

\subsubsection{Flood Extent Identification}

After the segmentation step, all pre- and post-flood Landsat 8 images and DEM layers were inputted into the classification process. We then computed the Normalized Difference Water Index $($ NDWI $=($ Green - SWIR $) /($ Green + SWIR $))$, Normalized Difference Vegetation Index $($ NDVI $=($ NIR Red) $/(\mathrm{NIR}+\mathrm{Red}))$, the difference in NDWI $\left(\mathrm{NDWI}_{\text {post }}-\mathrm{NDWI}_{\text {pre }}\right)$ and the difference in NDVI $\left(\mathrm{NDVI}_{\text {post }}-\mathrm{NDVI}_{\mathrm{pre}}\right.$ ), and elevation of all objects in the entire image. The decision tree approach was applied to detect the flood-inundated areas based on the changes in the spectral information and the indices between the pre- and post-flood images. The entire structure of the decision tree approach is shown in Figure 4. The thresholds of the spectral responses and indices were estimated using the flood reference map, and high spatial resolution images are from the Google Earth images.

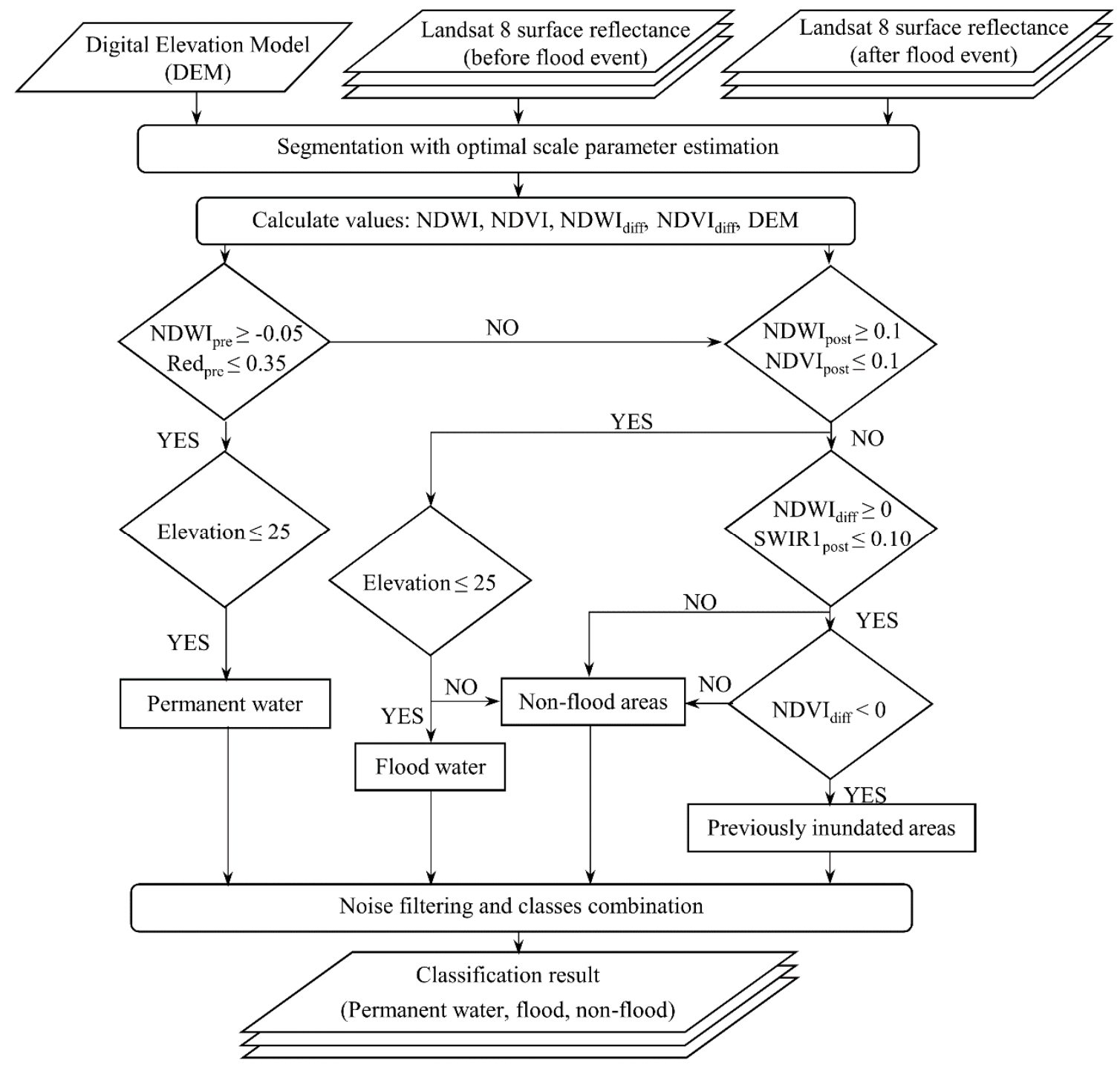

Figure 4. Flow chart of the decision tree approach for flood classification for the Landsat data. Subscripts pre, post, and diff indicate the terms pre-flood, post-flood, and the difference between pre- and post-flood stages, respectively. 
First, the permanent water bodies were identified using the thresholds of pre-flood water index (NDWI pre $\geq-0.05)$ and spectral response in band Red (Redpre $\leq 0.35)$. Over the non-permanent water regions, the currently inundated area was classified using thresholds of NDWI and NDVI $\left(\mathrm{NDWI}_{\text {post }} \geq 0.1\right.$, and NDVI $I_{\text {post }} \leq 0.1$ ). The satellite images can be captured several days after the day of peak flood water level. However, the previously inundated region could be delineated through the changes in NDVI value between the pre- and post-flood images, especially the changes over vegetative areas $\left(\right.$ NDVI $\left._{\text {diff }} \leq 0\right)$ ). In addition, the 30-m digital elevation model (GDEM2) was used to mask out non-flood water at an elevation higher than 25 meters. The images were finally classified into three classes: permanent water, flood, and non-flood classes.

\subsubsection{Paddy Rice Detection}

A variable EVI/LSWI 2130 function was used for paddy rice monitoring and detection during the transplanting period $[2,47,48]$. A series of MODIS VI data were collected from day 001 to day 361 . Two hundred samples were selected throughout the study area over different land cover types to investigate the variation of the above indices in the year 2013. The time series profiles of $\mathrm{LSWI}_{2130}$ and EVI were constructed throughout the year 2013 (Figure 5) for analyzing the rice growth phenology, in order to identify the paddy rice field area. In this study, the crop phenology was categorized into three main stages [47]: flooding and transplanting, growing, and harvesting stages using time series profiles of EVI and LSWI2130. During the fallow stage, the LSWI2130 value is generally lower than that of the EVI (day 001 to day 145). In the transplanting stage, on the contrary, irrigation water for paddy rice cultivation leads to an increase in the $\mathrm{LSWI}_{2130}$ value (day 145 to day 209), which exceeds the EVI value by adding a coefficient T. The period from day 209 to day 337 was not considered as the transplanting period even though the $\mathrm{LSWI}_{2130}$ is higher than EVI because of the appearance of typhoon flood water.

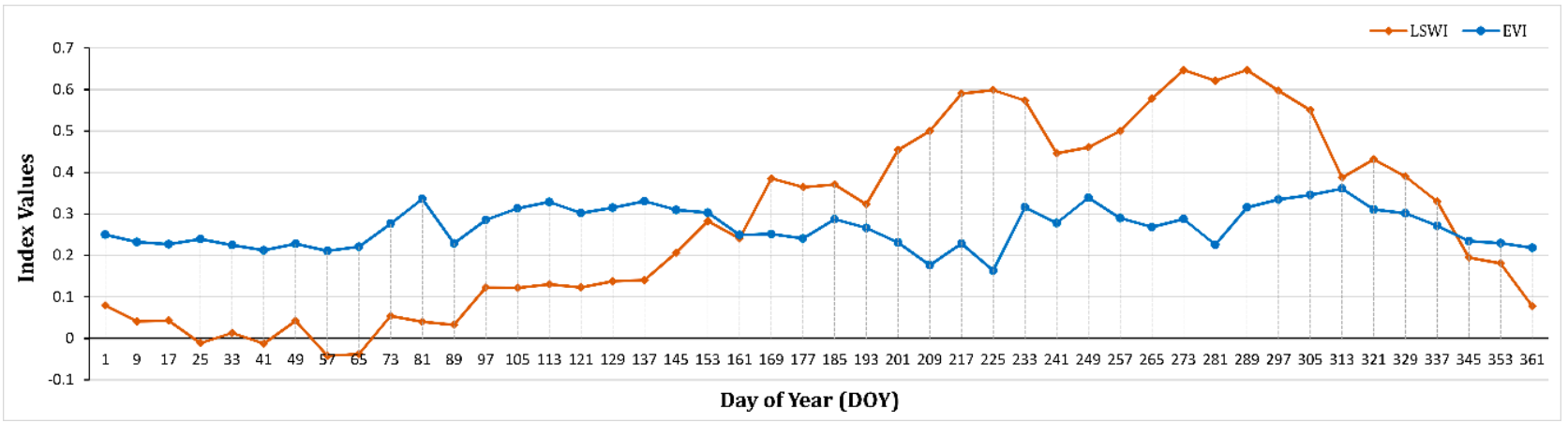

Figure 5. Profiles of EVI and $\mathrm{LSWI}_{2130}$ for the MODIS data over the paddy rice field throughout the year 2013 .

The relationship between the two indices (LSWI $2130+\mathrm{T} \geq \mathrm{EVI}$ ) was applied to identify the paddy rice field in the transplanting stage. As seen from the above line graph, the $\mathrm{LSWI}_{2130}$ values were, in the transplanting stage, always higher than those of the EVI if we add a coefficient due to the appearance of irrigation water. In this study, we selected $\mathrm{T}=0.1$. On the contrary, $\mathrm{LSWI}_{2130} \leq \mathrm{EVI}$ indicates the absence of irrigation water during the fallow stage. Persistent water bodies were masked out using a threshold EVI $\leq 0.15$ value during the dry season (day 033 to 133). Evergreen forest exhibits a high 
NDVI over a longer period throughout the year compared to the shorter rice growth phenology. The objects were masked out as evergreen forest if they were identified as NDVI $\geq 0.50$ for six consecutive months (day 49 to day 193). The elevation and slope maps were additionally employed to mask out the non-rice area above the elevation of 80 meters with slope of $45^{\circ}$.

\subsection{Affected Rice Field Estimation}

The affected paddy rice field was estimated by overlaying the flood extent map derived from the Landsat 8 data with the rice area map produced from the MODIS VI products. Due to the difference in the spatial resolution between Landsat and MODIS images, the overlaying process was implemented on vector format. Accordingly, the flood and rice maps were converted from raster to vector format, and the affected paddy rice areas were derived using the overlay operator. The detailed flood damage statistics at province, district, and commune levels were further analyzed by the ArcMap software.

\section{Results and Discussion}

\subsection{Image Segmentation}

The segmentation result of the Landsat images with optimal scale parameter of 23 (shape $=0.1$, compactness $=0.5$ ) is illustrated in Figure 6 . The segmentation result of the MODIS series with an optimal scale parameter of 11 and the same shape and compactness are shown in Figure 7.
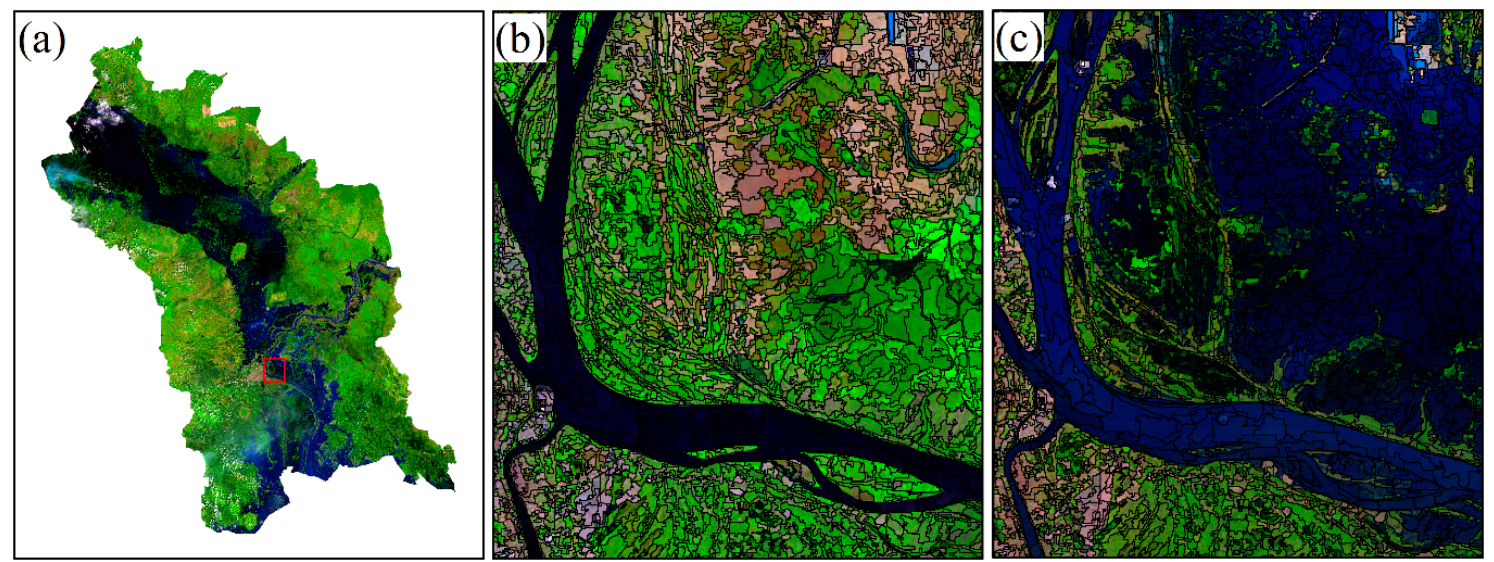

Figure 6. Segmentation result (scale parameter $=23$, shape $=0.1$, compactness $=0.5$ ):

(a) the entire Landsat 8 mosaicked image; and (b) pre-flood and (c) post-flood image subsets.

It is seen that the inundation areas were separated from non-water land cover in the Landsat images. Both pre- and post-flood images were included in the segmentation process. Thus, the water inundation objects were also segmented into smaller objects, which represent the land types of the pre-flood stage for the change detection of the water cover. For the MODIS images, the homogeneous areas were clustered into various objects based on the multi-temporal spectral response series. The boundaries of the objects in the MODIS images are not smooth because of the coarse resolution at $250 \mathrm{~m}$. In fact, the segmentation was thoroughly conducted with an optimal scale parameter. Therefore, this is the optimal segmentation result of the image, and if the scale parameter increases, it will lead to under-segmentation and misclassification of the paddy rice field. 

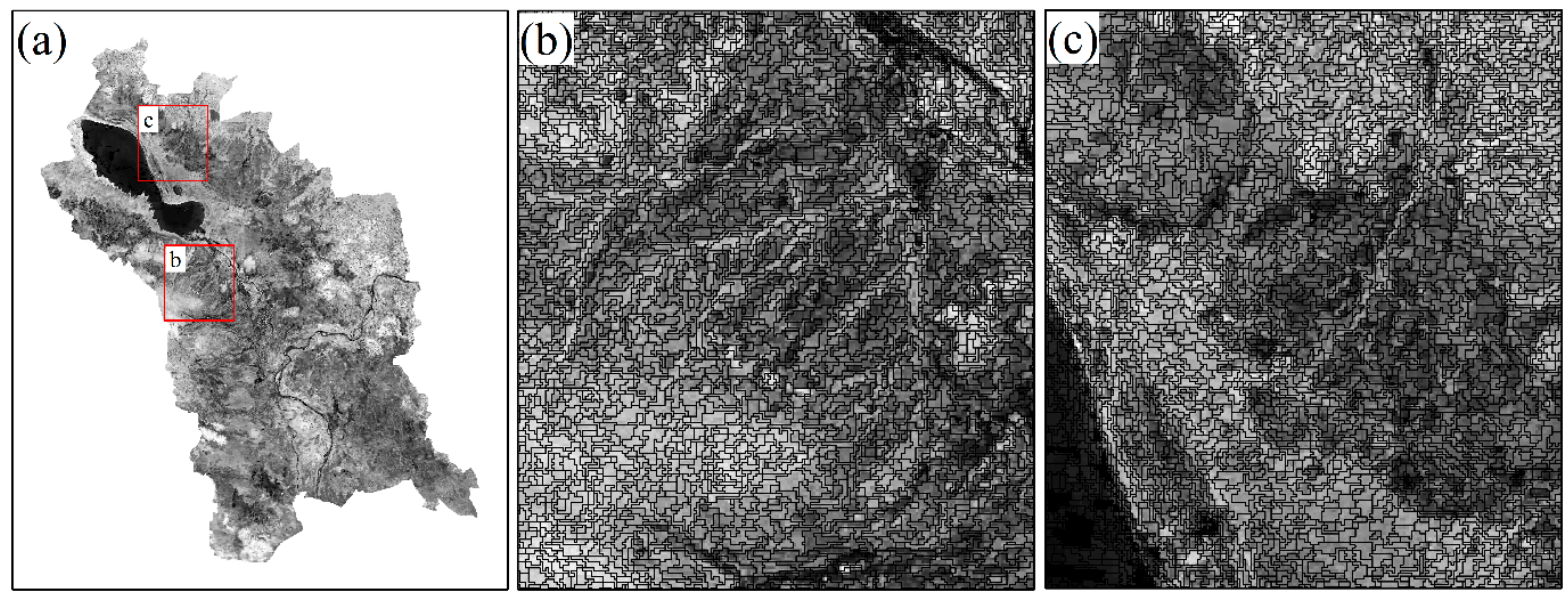

Figure 7. Segmentation result of the MODIS time series (scale parameter $=11$, shape $=0.1$, compactness $=0.5)$ : (a) the entire image; and $(\mathbf{b})$ and $(\mathbf{c})$ visualizing subsets.

\subsection{Flood Extent Map}

The classification result of the flood-inundated areas in Cambodia in 2013 is shown in Figure 8. The inundated regions normally occurred along both sides of the Mekong River and Tonle Sap Lake. The previously flooded areas in the northwestern region were still identified after several days of peak flood water and water evacuation based on changes in the spectral response, and vegetation and water indices.

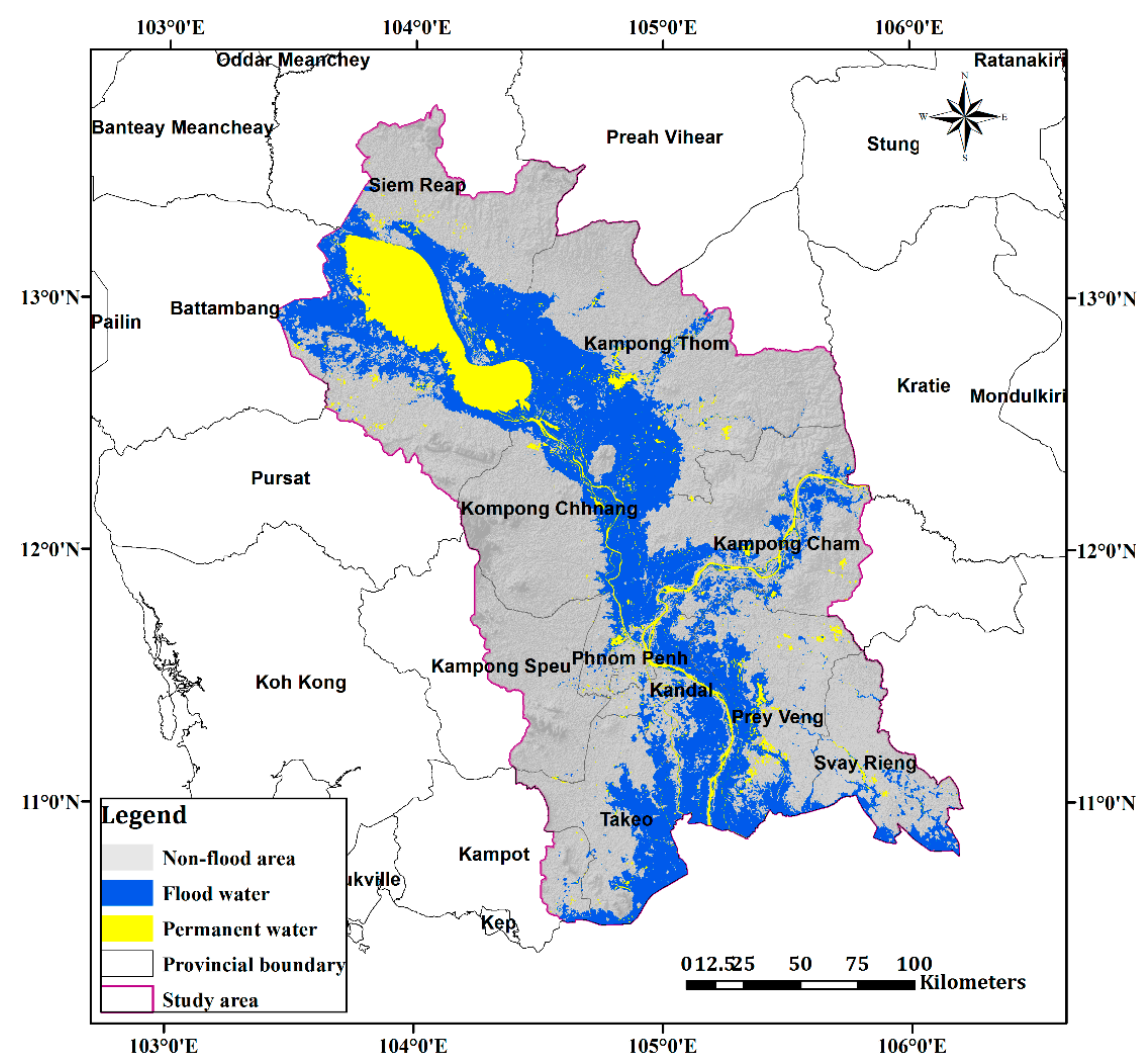

Figure 8. Flood inundation extraction result from the Landsat 8 images.

The most inundated areas are in the central region, which is vegetated by mixed forest surrounded by the paddy rice field in the lowland floodplain regions. Therefore, the flood significantly affected the 
population in the rural areas, who heavily rely on paddy rice production. The aquacultural production in the Mekong River and Tonle Sap Lake regions was also seriously impacted, and needed to be thoroughly investigated.

\subsection{Paddy Rice Map}

The paddy rice field (Figure 9) is mainly distributed in the central region of the country around water supplying systems with high density concentration, especially in the southeastern downstream floodplain of the Mekong River. The geomorphological stand of the paddy rice field makes it the most flood-vulnerable crop region during the monsoon seasons.

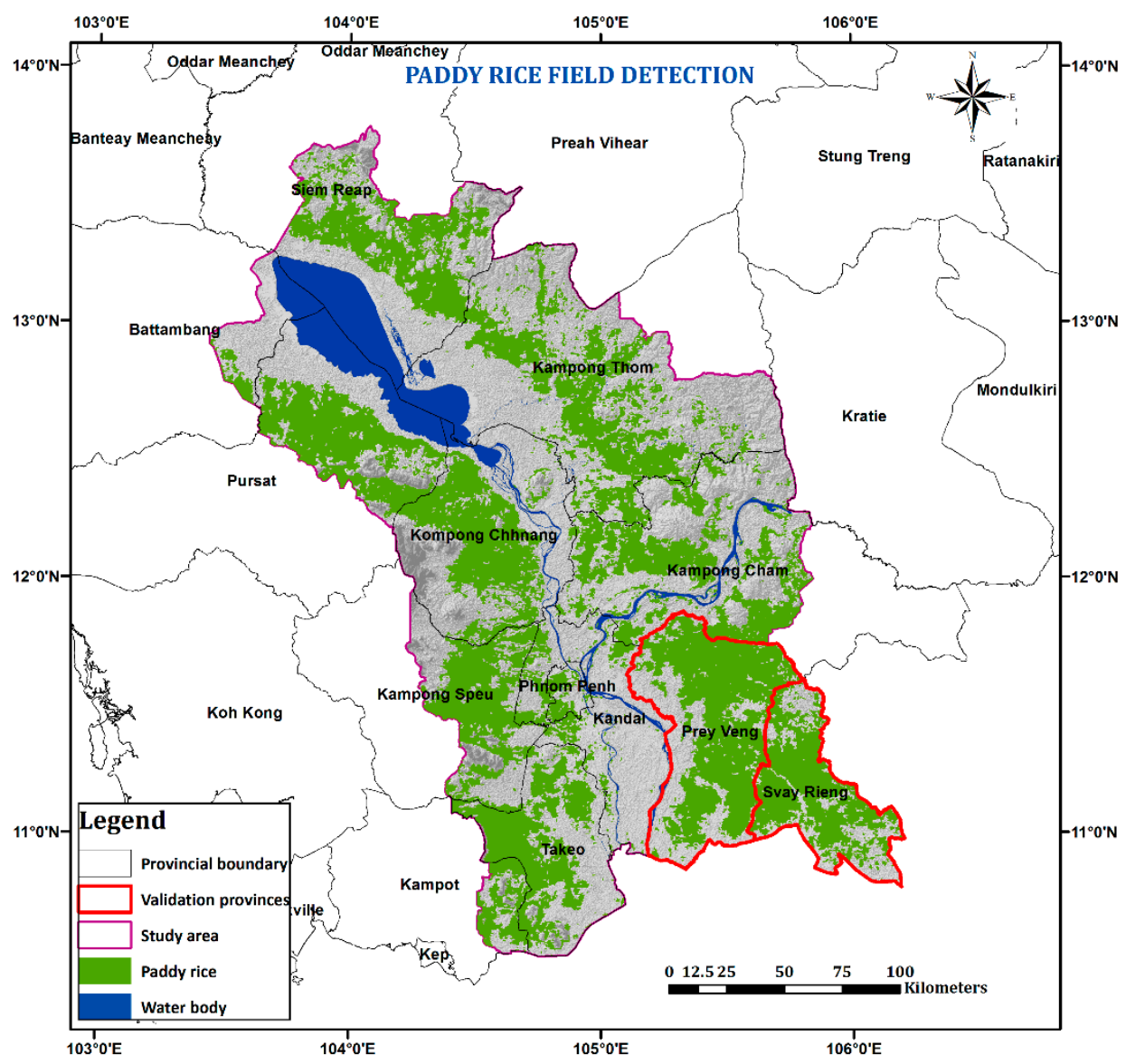

Figure 9. Paddy rice area map derived from the MODIS VI products.

The Prey Veng and Svay Rieng provinces, of which the boundaries are in red, were selected for accuracy assessment. There are 196 communes in total, with 116 in Prey Veng and 80 in Svay Rieng. However, 16 communes consist of not only wet season rice, but also of dry season crop areas (November to April). In this study, we only classified the wet season paddy rice, which is cultivated during the rainy season from May to November, and affected during the flood disaster in October 2013. Hence, only 180 communes were studied in this study. 


\subsection{Affected Rice Field Estimation}

For the damage assessment, the flood inundation map was overlaid with the MODIS-derived rice map to obtain the affected rice area. The ArcMap software was used for further analysis to estimate detailed flood statistics at province, district, and commune levels. The affected rice areas are illustrated in Figure 10, and flood statistics at province level are representatively shown in Table 3. As seen, the total rice area affected during the flood event was 231,715 hectares within the study area. Kampong Thom and Prey Veng, in the lowland floodplain in the middle and downstream of the Mekong River, appeared to be the most vulnerable provinces with rice-affected area of 66,503 and 43,180 hectares, respectively. The agricultural losses in this event could cause long-term adverse impacts on the local communities. Thus, the post-flood response should be thoroughly planned to deal with the negative effects, and to preserve the benefits to soil moisture, fertility for agriculture, surface water recharge, and ecological benefits for fisheries of inundation water.

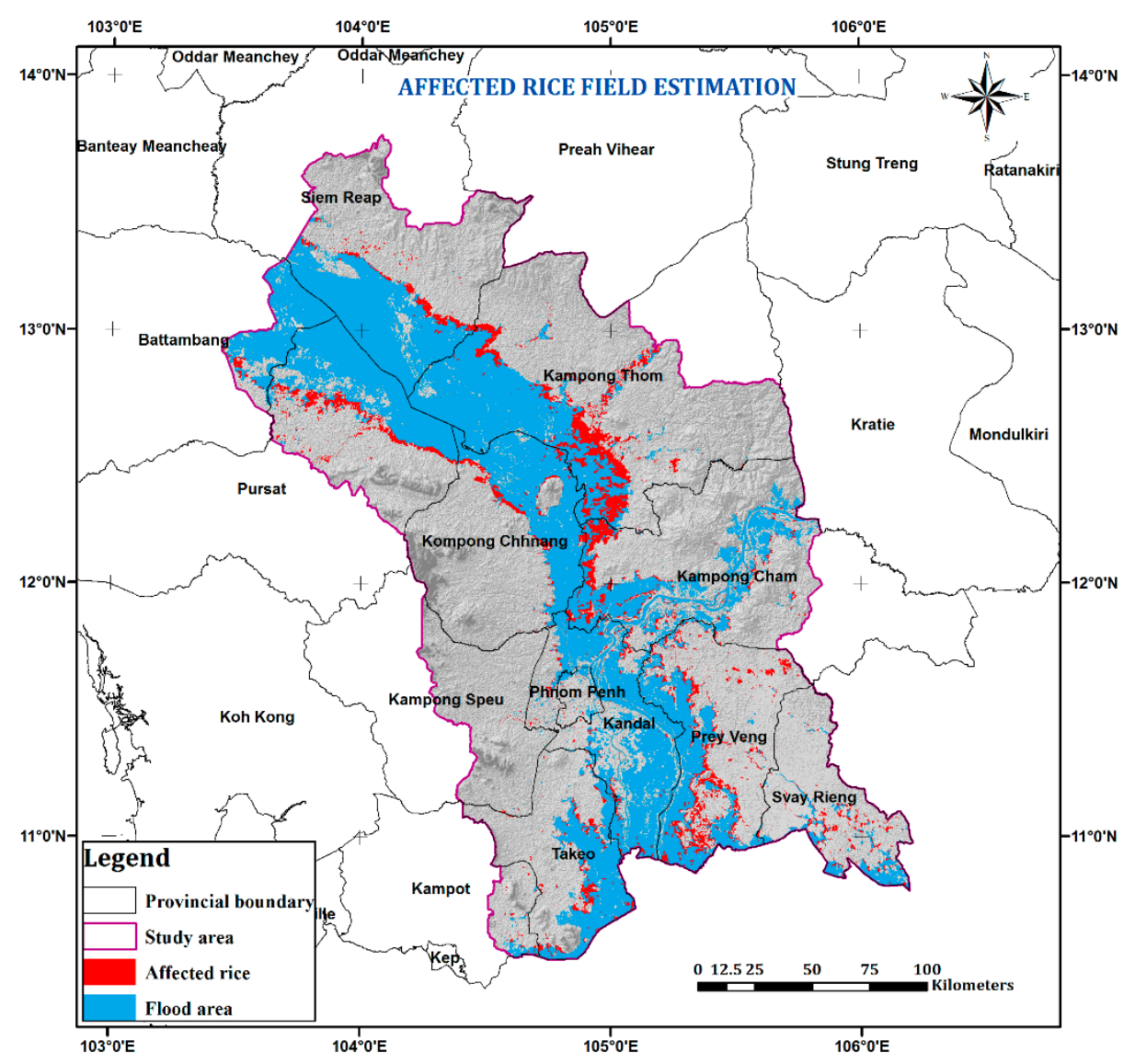

Figure 10. Affected paddy rice estimation.

\subsection{Validation}

\subsubsection{Validation of Flood Extent Classification}

The classification of the flood-inundated water from the Landsat 8 data collected on 24 October 2013 was validated with classification result from the other two data sources. The flood-inundated area maps derived from the Pleiades satellite images with a spatial resolution of 0.5 meters collected on 
October 22, 2013 and the DMC satellite data with a spatial resolution of $22 \mathrm{~m}$ captured on 24 October 2013. In this study, not only were the currently flood water areas detected, but also the previously inundated regions can be delineated, based on changes in the vegetation index between the pre- and post-flood images, especially associated with the changes over the vegetated areas. Therefore, the flood map produced from the Pleiades satellite images collected on 22 October 2013 was used to evaluate the feasibility of the approach. It is supposed that the two satellite data with higher spatial resolution provide more accurate flood maps, which can be considered as reference data for validating the Landsat-derived flood classification results by constructing the contingent matrix and determining the accuracy assessment criteria. The detailed information of the accuracy assessment for the inundation map is given in Table 4.

Table 3. Flood-inundated and -affected paddy rice area statistics.

\begin{tabular}{cccc}
\hline No. & Province Name & Inundated Area (ha) & Affected Rice Area (ha) \\
\hline 1 & Battambang & 90,386 & 2834 \\
2 & Kampong Cham & 170,911 & 31,720 \\
3 & Kampong Speu & 1016 & 574 \\
4 & Kampong Thom & 314,528 & 66,503 \\
5 & Kampot & 6935 & 1523 \\
6 & Kandaal & 207,940 & 8487 \\
7 & Kompong Chnang & 173,612 & 14,108 \\
8 & Kratie & 2 & 0 \\
9 & Phnom Penh & 6790 & 730 \\
10 & Prey Veng & 168,081 & 43,180 \\
11 & Pursat & 177,099 & 23,022 \\
12 & Siem Reap & 205,871 & 14,251 \\
13 & Svay Rieng & 40,592 & 11,170 \\
14 & Takeo & 119,336 & 13,613 \\
\hline Total & & $1,683,099$ & 231,715 \\
\hline
\end{tabular}

Table 4. Validation of the flood map with the Pleiades- and DMC-derived results (PA: producer accuracy; UA: user accuracy, OA: overall accuracy, and Kappa: inter-observer Kappa Statistic).

\begin{tabular}{ccccccc}
\hline Classified & \multicolumn{2}{c}{ Reference Data (pixel) } & \multicolumn{2}{c}{ Assessing Criteria } \\
\cline { 2 - 7 } Inundation (pixel) & Flood & Non-Flood & PA (\%) & UA (\%) & OA (\%) & Kappa \\
\hline \multicolumn{7}{c}{ Compared to Pleiades result } \\
\hline Flood & 130,677 & 4421 & 96.18 & 96.73 & 96.68 & 0.93 \\
Non-flood & 5192 & 149,413 & 97.13 & 96.64 & -- & -- \\
\hline Flood & $12,504,899$ & 301,473 & 89.80 & 97.65 & 95.09 & 0.90 \\
Non-flood & $1,418,931$ & $20,782,739$ & 98.57 & 93.60 & -- & -- \\
\hline
\end{tabular}

\subsubsection{Validation of Paddy Rice Detection}

The paddy rice classification result was validated using the statistical rice ratio and area at the commune level in the two provinces, Prey Veng and Svay Rieng. We employed a linear regression model to 
evaluate the relationship between the MODIS-derived and the statistical rice area. The rice ecosystem map was used to reject the dry season rice areas, which are included in the rice statistical data. Sixteen communes out of the 196 that contain dry season rice were rejected from the validation process. The linear regression models, representing the relationship between the derived rice area and the reference data, are shown in Figure 11.
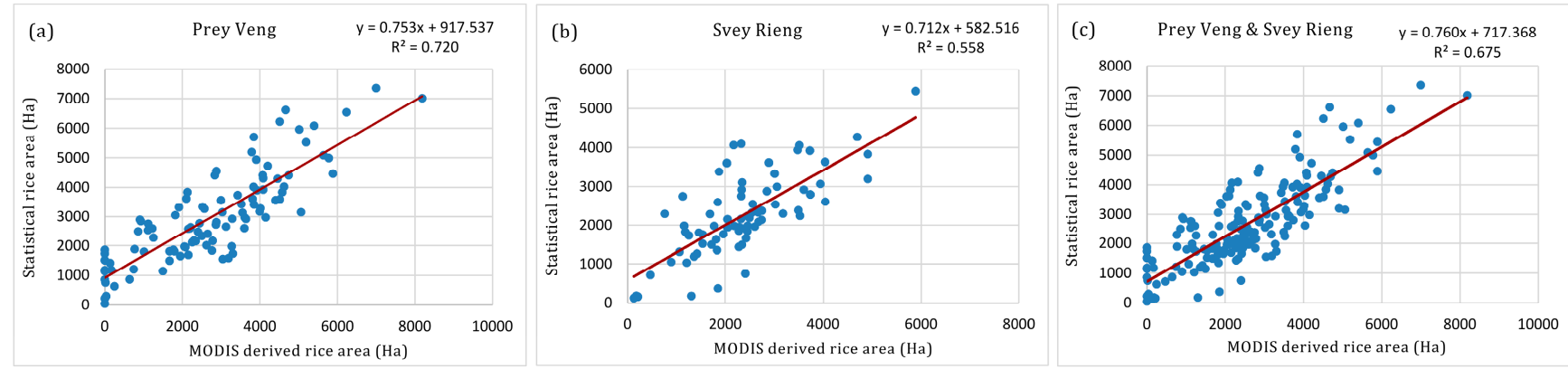

Figure 11. Comparison between the MODIS-derived and statistical rice area in (a) Prey Veng; (b) Svay Rieng; and (c) both provinces.

The MODIS-derived rice areas were at a high degree of agreement in comparison with the commune-level statistical data. The correlation coefficient $\left(R^{2}=0.720\right)$ in Prey Veng was higher than that in Svay Rieng province $\left(R^{2}=0.558\right)$. In the two regions, the coefficient was $R^{2}=0.675$, which is moderately good for rice management and updating purposes. The difference between estimated and statistical rice is due to the coarse resolution of the MODIS data, and the distortion of the statistical approach.

\subsubsection{Validation of Affected Rice Estimation}

Due to the lack of a rice-affected map and detailed flood damage information, we compared the total rice-affected area estimated from our approach with that of the statistical data provided by the Cambodian government. The total rice area impacted by the disaster in October 2013 was 384,846 ha, as reported in [13]. The northwest region of the country was covered by cloud on the days of the Landsat image acquisition. Therefore, we deduced the rice damaged area of 147,294 ha by overlaying the rice classification map with the flood inundation area that resulted from the DMC and Radarsat- 2 satellite images before the comparison process. The slight difference of $2.52 \%$ between the deducted area $(237,552 \mathrm{ha})$ and the result from the study (231,715 ha) shows that the integration of the multi-sensor optical satellite data can be effectively utilized to observe the flood inundation and evaluate the impacts on agricultural production, especially, damage to paddy rice cultivation.

\section{Conclusions}

This study introduced an object-based approach for the flood mapping and affected rice field estimation using the Landsat 8 OLI and MODIS vegetation index products. The object-based image analysis approach was effectively applied in both flood mapping and rice detection with an employment of optimal scale parameter estimation in the image segmentation process. The flood classification result exhibits a high degree of agreement with the outcome of the finer spatial resolution 
imagery (overall accuracy $96.68 \%$ and Kappa coefficient 0.93 with Pleiades, and overall accuracy 95.09\% and Kappa coefficient 0.90 with DMC data). The paddy rice detection outcome was consistent with the commune-level statistical data $\left(R^{2}=0.675\right)$. The details on affected rice area estimated from the study can provide the local government with valuable information for post-flood compensation and restoration strategies.

The northwest region of the country was covered by cloud on the acquisition date of the Landsat 8 images, and it limits the flood inundation mapping of the Landsat data in this area. Therefore, the Landsat/MODIS image fusion approach [49-51] could be applied to obtain inundation maps at the Landsat image scale in future studies. The fusion approach can also be applied for the monitoring and detection of the paddy rice area at the Landsat image scale. The band weighting process for the different spectral bands should be further considered to achieve better segmentation and classification results for the inundation water.

\section{Acknowledgments}

This research was partially supported by National Central University, Taiwan through the NCU International Student Scholarship and research grants MOST 103-2111-M-008 -023 and 103-2221-E-008 -074. The authors would like to thank the United States Geological Survey (USGS), the International Charter for Space and Major Disasters, and Open Development Cambodia for providing the satellite and ancillary data used in this study.

\section{Author Contributions}

The main idea of the paper arose from a discussion between two of the authors, Phuong D. Dao and Yuei-An Liou, advisor of the former. Phuong D. Dao conducted the data acquisition, processing, and analysis. Phuong D. Dao and Yuei-An Liou wrote the paper. Yuei-An Liou provided general advice and revisions, and made important contributions to the Discussion and Conclusions sections.

\section{Conflicts of Interest}

The authors declare no conflict of interest.

\section{References}

1. Hall, D.; Bouapao, L. Social Impact Monitoring and Vulnerability Assessment; Regional report; Mekong River Commission: Vientiane, Laos, 2010.

2. Liou, Y.-A.; Sha, H.-C.; Chen, T.-M.; Wang, T.-S.; Li, Y.-T.; Lai, Y.-C.; Chiang, M.-H.; Lu, L.-T. Assessment of disaster losses in rice paddy field and yield after tsunami induced by the 2011 great east japan earthquake. J. Mar. Sci. Technol. 2012, 20, 618-623.

3. Hussaina, E.; Urala, S.; Malikb, A.; Shana, J. Mapping Pakistan 2010 floods using remote sensing data. In Proceedings of the ASPRS Annual Conference, Milwaukee, WI, USA, 1-5 May 2011.

4. Mallinis, G.; Gitas, I.Z.; Giannakopoulos, V.; Maris, F.; Tsakiri-Strati, M. An object-based approach for flood area delineation in a transboundary area using Envisat ASAR and Landsat TM data. Int. J. Digit. Earth 2011, 6, 1-13. 
5. Uddin, K.; Gurung, D.R.; Giriraj, A.; Shrestha, B. Application of remote sensing and gis for flood hazard management: A case study from Sindh Province, Pakistan. Am. J. Geogr. Inf. Syst. 2013, 2, $1-5$.

6. Sanyal, J.; Lu, X. Application of remote sensing in flood management with special reference to Monsoon Asia: A review. Nat. Hazards 2004, 33, 283-301.

7. Gianinetto, M.; Villa, P.; Lechi, G. Postflood damage evaluation using Landsat TM and ETM+ data integrated with DEM. IEEE Trans. Geosci. Remote Sens. 2006, 44, 236-243.

8. Chau, V.N.; Holland, J.; Cassells, S.; Tuohy, M. Using gis to map impacts upon agriculture from extreme floods in Vietnam. Appl. Geogr. 2013, 41, 65-74.

9. Oh, M.; Komatsu, S. Characterization of proteins in soybean roots under flooding and drought stresses. J. Proteomics 2014, 114, 161-181.

10. Kamal, A.H.M.; Rashid, H.; Sakata, K.; Komatsu, S. Gel-free quantitative proteomic approach to identify cotyledon proteins in soybean under flooding stress. J. Proteomics 2015, 112, 1-13.

11. Bhatt, R.M.; Upreti, K.K.; Divya, M.; Bhat, S.; Pavithra, C.; Sadashiva, A. Interspecific grafting to enhance physiological resilience to flooding stress in tomato (solanum lycopersicum 1.). Sci. Hortic. 2015, 182, 8-17.

12. Sakamoto, T.; van Nguyen, N.; Kotera, A.; Ohno, H.; Ishitsuka, N.; Yokozawa, M. Detecting temporal changes in the extent of annual flooding within the cambodia and the Vietnamese Mekong Delta from modis time-series imagery. Remote Sens. Environ. 2007, 109, 295-313.

13. Royal Government of Cambodia. Post-Flood Early Recovery Need Assessment Report; Royal Government of Cambodia Report; Royal Government of Cambodia: Phnom Penh, Cambodia, 2014.

14. Tapia-Silva, F.-O.; Itzerott, S.; Foerster, S.; Kuhlmann, B.; Kreibich, H. Estimation of flood losses to agricultural crops using remote sensing. Phys. Chem. Earth Parts $A / B / C$ 2011, 36, 253-265.

15. Bertin, X.; Li, K.; Roland, A.; Zhang, Y.J.; Breilh, J.F.; Chaumillon, E. A modeling-based analysis of the flooding associated with xynthia, Central Bay of Biscay. Coast. Eng. 2014, 94, 80-89.

16. Rogger, M.; Kohl, B.; Pirkl, H.; Viglione, A.; Komma, J.; Kirnbauer, R.; Merz, R.; Blöschl, G. Runoff models and flood frequency statistics for design flood estimation in Austria-Do they tell a consistent story? J. Hydrol. 2012, 456, 30-43.

17. Rudari, R.; Gabellani, S.; Delogu, F. A simple model to map areas prone to surface water flooding. Int. J. Disaster Risk Reduct. 2014, 10, 428-441.

18. Henry, J.B.; Chastanet, P.; Fellah, K.; Desnos, Y.L. Envisat multi-polarized ASAR data for flood mapping. Int. J. Remote Sens. 2006, 27, 1921-1929.

19. Evans, T.L.; Costa, M.; Telmer, K.; Silva, T.S. Using ALOS/PALSAR and RADARSAT-2 to map land cover and seasonal inundation in the Brazilian Pantanal. IEEE J. Sel. Top. Appl. Earth Obs. Remote Sens. 2010, 3, 560-575.

20. Oruc, M.; Marangoz, A.; Buyuksalih, G. Comparison of Pixel-based and object-oriented classification approaches using landsat-7 ETM spectral bands. In Proceedings of the ISRPS 2004 Annual Conference, Istabul, Turkey, 19-23 July 2004; pp. 19-23.

21. Matinfar, H.; Sarmadian, F.; AlaviPanah, S.; Heck, R. Comparisons of object-oriented and pixel-based classification of land use/land cover types based on Landsat7, ETM+ spectral bands (case study: Arid region of Iran). Am. Eur. J. Agric. Environ. Sci. 2007, 2, 448-456. 
22. Devadas, R.; Denham, R.J.; Pringle, M. Support vector machine classification of object-based data for crop mapping, using multi-temporal landsat imagery. Int. Arch. Photogramm. Remote Sens. Spat. Inf. Sci. 2012, XXXIX-B7, 185-190.

23. Heumann, B.W. An object-based classification of mangroves using a hybrid decision tree-Support vector machine approach. Remote Sens. 2011, 3, 2440-2460.

24. Dronova, I.; Gong, P.; Wang, L.; Zhong, L. Mapping dynamic cover types in a large seasonally flooded wetland using extended principal component analysis and object-based classification. Remote Sens. Environ. 2015, 158, 193-206.

25. Dronova, I.; Gong, P.; Wang, L. Object-based analysis and change detection of major wetland cover types and their classification uncertainty during the low water period at Poyang Lake, China. Remote Sens. Environ. 2011, 115, 3220-3236.

26. Frohn, R.; Autrey, B.; Lane, C.; Reif, M. Segmentation and object-oriented classification of wetlands in a Karst Florida landscape using multi-season Landsat-7 ETM+ imagery. Int. J. Remote Sens. 2011, 32, 1471-1489.

27. Blaschke, T. Object based image analysis for remote sensing. ISPRS J. Photogramm. Remote Sens. 2010, 65, 2-16.

28. Bisquert, M.; Bégué, A.; Deshayes, M. Object-based delineation of homogeneous landscape units at regional scale based on MODIS time series. Int. J. Appl. Earth Obs. Geoinf. 2015. 37, 72-82.

29. Thompson, J.A.; Lees, B.G. Applying object-based segmentation in the temporal domain to characterise snow seasonality. ISPRS J. Photogramm. Remote Sens. 2014, 97, 98-110.

30. Vintrou, E.; Desbrosse, A.; Bégué, A.; Traoré, S.; Baron, C.; lo Seen, D. Crop area mapping in west Africa using landscape stratification of MODIS time series and comparison with existing global land products. Int. J. Appl. Earth Obs. Geoinf. 2012, 14, 83-93.

31. Le Maire, G.; Dupuy, S.; Nouvellon, Y.; Loos, R.A.; Hakamada, R. Mapping short-rotation plantations at regional scale using MODIS time series: Case of eucalypt plantations in Brazil. Remote Sens. Environ. 2014, 152, 136-149.

32. Gao, Y.; Mas, J.; Niemeyer, I.; Marpu, P.; Palacio, J. Object-based image analysis for mapping land-cover in a forest area. In Proceedings of the 5th International Symposium: Spatial Data Quality, Enschede, The Netherlands, 13-15 June 2007; pp. 13-15.

33. Nesbitt, H.J. Rice Production in Cambodia; International Rice Research Institute: Laguna, Philippines, 1997.

34. Men, S.; Ram, C.; Edwin, J.; Ouk, M.; Sakhan, S.; Hun, Y.; Pith, K.; Khun, L.; Sidhu, G.; Sin, S. Description of Rice Varieties Released by the Varietal Recommendation Committee of Cambodia (1999-2000); Cambodian Agricultural Research and Development Institute: Phnom Penh, Cambodia, 2001.

35. Vang, S. Country report on rice cultivation pratice. In Proceedings of the Expert Meeting, Bandkok, Thailand, 2-3 June 2011.

36. Knight, E.J.; Kvaran, G. Landsat-8 Operational Land Imager design, characterization and performance. Remote Sens. 2014, 6, 10286-10305.

37. Williams, D. Landsat 7 Science Data Users Handbook; NASA: Washington, DC, USA, 2008, Volume 12, p. 2008. 
38. ITT Visual Information Solutions, I.V.I. Atmospheric Correction Module: Quac and Flaash User's Guide, Version 4.7; ITT Visual Information Solutions: Boulder, CO, USA, 2009.

39. Didan, K.; Huete, A. Modis Vegetation Index Product Series Collection 5 Change Summary; Terrestrial Biophysics and Remote Sensing (TBRS) Laboratory, The University of Arizona: Tucson, AZ, USA, 2006; Volume 29, p. 2006.

40. Trimble. Ecognition Developer 8.7 User Guide; Trimble Documentation: Munich, Germany, 2011; p. 258.

41. Happ, P.; Ferreira, R.; Bentes, C.; Costa, G.; Feitosa, R. In Multiresolution Segmentation: A Parallel Approach for High Resolution Image Segmentation in Multicore Architectures. In Proceedings of the 3rd International Conference on Geographic Object-Based Image Analysis, Ghent, Belgium, 29 June-2 July 2010.

42. Baatz, M.; Schäpe, A. Multiresolution segmentation: An optimization approach for high quality multi-scale image segmentation. In Angewandte Geographische Informationsverarbeitung XII. Beiträge zum AGIT-Symposium Salzburg 2000; Strobl, J., Blaschke, T., Griesebner, G., Eds.; Wichmann: Heidelberg, Germany, 2000; pp. 12-23.

43. Gao, Y.; Mas, J.F.; Kerle, N.; Navarrete Pacheco, J.A. Optimal region growing segmentation and its effect on classification accuracy. Int. J. Remote Sens. 2011, 32, 3747-3763.

44. Drăguţ, L.; Csillik, O.; Eisank, C.; Tiede, D. Automated parameterisation for multi-scale image segmentation on multiple layers. ISPRS J. Photogr. Remote Sens. 2014, 88, 119-127.

45. Drăguţ, L.; Tiede, D.; Levick, S.R. Esp: A tool to estimate scale parameter for multiresolution image segmentation of remotely sensed data. Int. J. Geogr. Inf. Sci. 2010, 24, 859-871.

46. Woodcock, C.E.; Strahler, A.H. The factor of scale in remote sensing. Remote Sens. Environ. 1987, 21, 311-332.

47. Peng, D.; Huete, A.R.; Huang, J.; Wang, F.; Sun, H. Detection and estimation of mixed paddy rice cropping patterns with modis data. Int. J. Appl. Earth Obs. Geoinf. 2011, 13, 13-23.

48. Xiao, X.; Boles, S.; Liu, J.; Zhuang, D.; Frolking, S.; Li, C.; Salas, W.; Moore III, B. Mapping paddy rice agriculture in southern china using multi-temporal MODIS images. Remote Sens. Environ. 2005, 95, 480-492.

49. Walker, J.; de Beurs, K.; Wynne, R.; Gao, F. Evaluation of Landsat and MODIS data fusion products for analysis of dryland forest phenology. Remote Sens. Environ. 2012, 117, 381-393.

50. Hilker, T.; Wulder, M.A.; Coops, N.C.; Linke, J.; McDermid, G.; Masek, J.G.; Gao, F.; White, J.C. A new data fusion model for high spatial-and temporal-resolution mapping of forest disturbance based on landsat and modis. Remote Sens. Environ. 2009, 113, 1613-1627.

51. Gao, F.; Masek, J.; Schwaller, M.; Hall, F. On the blending of the Landsat and MODIS surface reflectance: Predicting daily landsat surface reflectance. IEEE Trans. Geosci. Remote Sens. 2006, 44, 2207-2218.

(C) 2015 by the authors; licensee MDPI, Basel, Switzerland. This article is an open access article distributed under the terms and conditions of the Creative Commons Attribution license (http://creativecommons.org/licenses/by/4.0/). 